\title{
A study of greater palatine foramen and its importance in the application of maxillary nerve block in south Indian population
}

\section{Aravinth Mahesh ${ }^{1}$, Rajesh.S *2.}

${ }^{1}$ Associate Professor, Department of Anatomy, Noorul Islam College of Dental Sciences, Aralumoodu, Neyyatinkara, Thiruvananthapuram, 695123, India.

${ }^{2}$ Associate professor, Department of Anatomy, SreeGokulam Medical College and Research Institute, Venjaramoodu, Trivandrum, 695607, India.

\section{ABSTRACT}

Introduction:The greater palatine foramen (GPF) is located in the posterior part of the hard palate between the articulations of hard palate with the maxilla. GPF continues posteriorly and upwards as greater palatine canal (GPC) which opens in to the inferior wall of pterygopalatine fossa. Exiting the foramen rotendum,maxillary nerve enters the pterygopalatine fossawhere it can be blocked. The intraoral route of GPF approach can be preferred for maxillary nerve block because of its low incidence of complications and high success rate. For achieving a painless intra operative period in procedures involving the maxillary region and for tooth extraction achieving a perfect maxillary nerve block is of at most importance.Our present study is aimed at correctly locating the position of GPF, its shape and patency in south Indian population which will be helpful for the intra oral approach of maxillary nerve block through the GPF

Materials and Methods: The study was conducted in 30 dry adult skull bones of both sex. The molar relation, shape and the patency of the GPF were observed, the readings were obtained, statistically analyzed and compared with other studies.

Results: In our observation on both side of skull, it was noted that GPF was located opposite to the $3^{\text {rd }}$ molar in $90 \%$ of cases. Oval shaped GPF is most commonly found in our study which accounts to $53.35 \%$ and the overall patency rate for GPF was $95 \%$ in our study.

Conclusion: Analysis and comparison of data has proven that the position, shape and patency of GPF may vary according to different races. This study has also confirmed that the maxillary nerve block via GPF is relatively safe and easier due to the consistency of the position, shape and the patency of the GPF in south Indian population.

KEY WORDS: Greater palatine foramen,maxillary nerve block, regional blocks, Greater palatine canal, pterygopalatine fossa, Maxillary nerve.

Corresponding Author: : Dr. Rajesh.S, Associate professor, Department of Anatomy, Sree Gokulam Medical College and Research Institute, Venjaramoodu, Trivandrum, 695607, India. Mobile no: 9042229402 E-Mail: drrajeshselvaraj@gmail.com

\begin{tabular}{|c|c|c|c|}
\hline Access this Article online & \multicolumn{3}{|c|}{ Journal Information } \\
\hline \multirow[t]{3}{*}{ Quick Response code } & \multicolumn{3}{|c|}{$\begin{array}{l}\text { International Journal of Anatomy and Research } \\
\text { ISSN (E) 2321-4287 | ISSN (P) 2321-8967 } \\
\text { https://www.ijmhr.org/ijar.htm } \\
\text { DOI-Prefix: https://dx.doi.org/10.16965/ijar } \quad \text { (cc) Er-Ne-si }\end{array}$} \\
\hline & \multicolumn{3}{|c|}{ Article Information } \\
\hline & $\begin{array}{l}\text { Received: } 10 \text { Nov } 2020 \\
\text { Peer Review: } 10 \text { Nov } 2020 \\
\text { Revised: None }\end{array}$ & $\begin{array}{l}\text { Accepted: } 29 \text { Dec } \\
\text { Published (O): } 30 \\
\text { Published (P): } 05\end{array}$ & $\begin{array}{l}20 \\
2021 \\
2021\end{array}$ \\
\hline
\end{tabular}

\section{INTRODUCTION}

The greater palatine foramen (GPF) is located in the posterior part of the hard palate between the articulations of hard palate with the maxilla. GPF continues posteriorly and upwards as greater palatine canal (GPC) which opens in to the inferior wall of pterygopalatine fossa. The maxillary nerve reaches the 
pterygopalatine fossa as it exits the middle cranial fossa through the foramen rotendum [1]. The maxillary nerve can be blocked as it exit the foramen rotendum [2].

For achieving a painless intra operative period in procedures involving the maxillary region and for tooth extraction achieving a perfect maxillary nerve block is of at most importance. The maxillary nerve block can be performed through intra oral and extra oral routes [3].The administration of local anesthetic through intra oral route can be done by two techniques, one around tuberosity, by high tuberosity technique and other through GPF [4].

The GPC approach through GPF is performed by injecting local anesthetic in the PPF to block maxillary nerve [5]. Through the intraoral route, the GPF approach can be preferred for maxillary nerve block because of its low incidence of complications like hematoma or over insertion of needle which are common in high tuberosity approach [6] and high success rate if performed after acquiring a proper anatomical knowledge of GPF and GPC [7]. This approach and the procedure remains an excellent method in achieving anesthesia in the maxilla during surgeries [2] or in diagnostic or therapeutic procedures in neuralgias like trigeminal neuralgia [6]. Regional anesthesia to hemi maxilla including teeth, mouth and parts of the nose is achieved via maxillary nerve block [5]. Maxillary nerve block achieves complete anesthesia of hemimaxilla with minimal needle penetration and less volume of anesthetic solution compared to alternative which involves at least four injections given together [6].

Greater Palatine canal approach: Place the needle next to the upper second molar over the palate while the patient keep the mouth wide open. Inject small quantity of anesthetic fluid once the needle reaches the hard palate. Once local anesthetic take effect in 5 minutes, reinsert the needle and advance through the greater palatine foramen in to the canal and inject the anesthetic fluid and gradually withdraw the needle [8].

The location of GPF is variable depending on the race of an individual. Our current study is aimed at correctly locating the position of greater palatine foramen which will be helpfulfor the intra oral approach of maxillary nerve block through the greater palatine foramen.

\section{MATERIALS AND METHODS}

The study was conducted in the Department of Anatomy of Sri Ramachandra Medical College and Research Institute, Sri Ramachandra University, Chennai. The study was conducted in 30 dry adult skull bones of both sex without any signs of erosions or any gross distortion due to any pathology. All the skulls included in the study were of adults as evidenced by the eruption of third molars. The molar relation, shape and the patency of the GPF were observed. The molar relation and shape of the foramen were recorded using simple observation by two investigators, the patency of the foramen is recorded using a 25 gauge orthodontic wire as probe (figure-1). The readings were obtained and statistically analyzed.

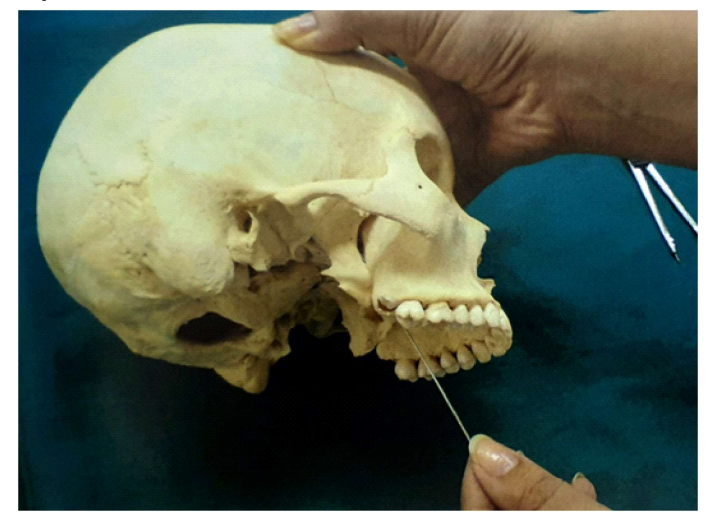

Fig. 1:Showing the procedure of Probing of GPF.

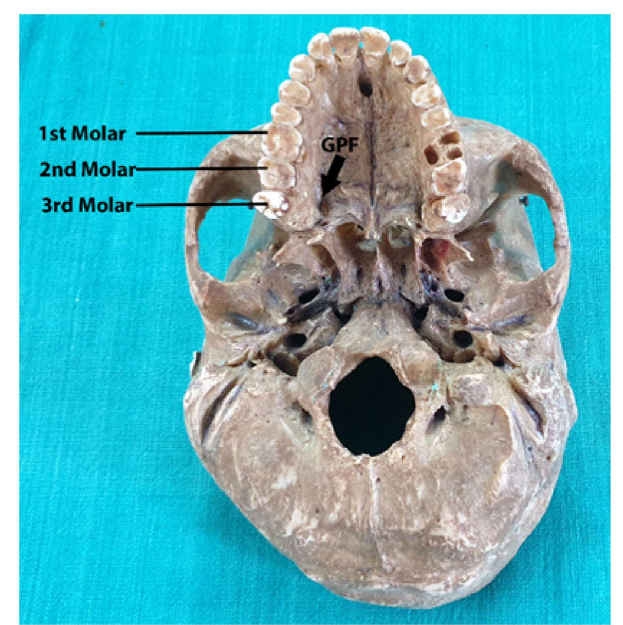

Fig. 2:Showing the procedure of Molar relation of GPF.

Recording of molar relation of GPF (figure-2): Depending on the relation of GPF to the 
molar tooth of upper jaw of the same side, it was classified to be in three different positions

1. Opposite to the $2^{\text {nd }}$ molar

2. Opposite to the $3^{\text {rd }}$ molar

3. Distal to the $3^{\text {rd }}$ molar

In our observation on both side of skull, it was noted that GPF was located opposite to the $3^{\text {rd }}$ molar in $90 \%$ of cases $(86.7 \%$ on the right and $93.3 \%$ on the left), opposite to $2^{\text {nd }}$ molar in only $3.3 \%$ of cases $(3.3 \%$ on the right and $3.3 \%$ on the left) and distal to the $3^{\text {rd }}$ molar in $6.65 \%$ of cases $(10 \%$ on the right and $3.3 \%$ on the left). The number wise distribution is shown in table -1 .

Recording shape of GPF:Out of 30 skulls (60 sides) $53.35 \%$ ( $56.7 \%$ of right and $50 \%$ of left) showed oval foramen, while $33.3 \%$ (33.3\% of right and $33.3 \%$ of left) showed round foramen and $13.35 \%$ was slit type (10\% of right and $16.7 \%$ of left).The number wise distribution is shown in table 1.

Table 1:Molar relation, Shape and Patency of GPF.

\begin{tabular}{cccccccccc}
\hline & \multicolumn{3}{c}{ Molar relation of GPF } & \multicolumn{3}{c}{ Shape of GPF } & \multicolumn{2}{c}{ Patency } \\
\cline { 2 - 10 } Side & $\begin{array}{c}\text { Opposite to } \\
2^{\text {nd }} \text { molar }\end{array}$ & $\begin{array}{c}\text { Opposite to } \\
\mathbf{3}^{\text {rd }} \text { molar }\end{array}$ & $\begin{array}{c}\text { Distal to } \\
\mathbf{3}^{\text {rd }} \text { molar }\end{array}$ & Oval & Round & Slit & yes & no \\
\hline Right side & 1 & 26 & 3 & 17 & 10 & 3 & 29 & 1 \\
Left side & 1 & 28 & 1 & 15 & 10 & 5 & 28 & 2 \\
\hline
\end{tabular}

Recording patency of GPF:Patency of left GPF was $93.3 \%$ and right GPF was $96.7 \%$. Overall patency rate was $95 \%$. Out of 30 skulls 1 of the right foramen and 2left foramina were not patent.The number wise distribution is shown in table -1

\section{DISCUSSION}

Molar relation:In our study concluded in the south Indian population skulls, majority of GPF occurs opposite to the 3rd molar. This finding is in accordance with the studies conducted by Saralaya et al [9], Ajmani [10], Hassanali et al [11] and Westmoreland et al [12] as shown in table 2.

Table 2:comparison of molar relation with other studies.

\begin{tabular}{lccc}
\hline \multicolumn{1}{c}{ Study } & Population & $\begin{array}{c}\text { Opposite to } \\
\mathbf{2}^{\text {nd }} \text { molar }\end{array}$ & $\begin{array}{c}\text { Opposite to } \\
\mathbf{3}^{\text {rd }} \text { molar }\end{array}$ \\
\hline Saralaya et al (2007) & Indian & $0.40 \%$ & $74.60 \%$ \\
Ajmani (1994) & Indian & $13 \%$ & $64.70 \%$ \\
Wang et al (1988) & Chinese & $17 \%$ & $33.50 \%$ \\
Hassanali et al (1984) & Kenyan African & $10.40 \%$ & $76 \%$ \\
Westmoreland et al (1982) & East Indians & $9.70 \%$ & $57 \%$ \\
Present study & South Indian & $3.30 \%$ & $90 \%$ \\
\hline
\end{tabular}

Int J Anat Res 2021, 9(1.1):7857-60. ISSN 2321-4287
Shape of GPF:In most of the studies conducted by methethrathip et al [7], Cheung et al [13] and Langenegger et al [14] the predominant type of shape of GPF is oval type, which is similar to our present study (55.35\%). In our study slit type is observed in $13.3 \%$ of skull GPF, this type of foramen may present with difficulty in negotiating the GPC through the GPF during maxillary nerve block procedure.

Patency of GPF:The overall patency is $95 \%$ in the present study $(96.7 \%$ on the right and 93.3\% on the left) which is comparable to the study conducted in Caucasians by Malamed et al [15] which is $97.55 \%$. Thus before attempting to give a maxillary nerve block through GPF, it may be kept in mind that around $5 \%$ of the GPF may be blind in south Indian population.

\section{CONCLUSION}

Maxillary nerve block is used mainly for the treatment procedures involving the surgeries of upper jaw, in cases where local blocks cannot be administered because of infection or abscess, surgeries of extensive trauma or cancer involving maxilla, congenital cleft palate repair, for post-operative pain relief following maxillary surgeries etc [2]. Maxillary nerve block via GPF and GPC can be safely and successfully administered by knowing the proper anatomical location shape and the incidence of patency of the foramen. This study has once again proven that the position, shape and patency of GPF may vary according to different races. This study has also confirmed that the maxillary nerve block via GPF is relatively safe and easier due to the consistency of the position, shape and the patency of the GPF in south Indian population.

\section{ACKNOWLEDGEMENTS}

We would like to thank the institution and the HOD of Anatomy department for their support and guidance.

\section{abbreviations}

GPF- Greater Palatine Foramen

GPC- greater Palatine Canal

Conflicts of Interests: None 


\section{REFERENCES}

[1]. Sai Pavithra R,Thenmozhi MS.Maxillary Nerve Variations and Its Clinical Significance.J. Pharm. Sci.\& Res 2014;6(4):203-5.

[2]. Aoun G, Zaarour I, Sokhn S, Nasseh I.Maxillary nerve block via the greater palatine canal: An old technique revisited.J Int Soc Prev Community Dent 2015; 5(5): 359-64.

[3]. Kanakaraj $M$, Shanmugasundaram N, Chandra mohan M, Kannan R, Perumal SM, Nagendran J.J Pharm Bioallied Sci 2012;4(2):S264-S269.

[4]. Bacci C, Ferrario S, Sivolella S, Menozzi G, Bartorelli LMG, Grossi GB, Zanette G.Maxillary nerve block: A comparison between the greater palatine canal and high tuberosity approaches.Italian Journal of Dental Medicine 2018;3(3):50-59.

[5]. Aoun G, Nasseh I, Sokhn S.Radio-anatomical Study of the Greater Palatine Canal and the Pterygopalatine Fossa in a Lebanese Population: A Consideration for Maxillary Nerve Block. Journal of Clinical Imaging Sciences 2016;6(1):1-7.

[6]. Stanley F Malamed. Handbook of local anesthesia. 7th edition; 2020:234.

[7]. Methathrathip D, Apinhasmit W, Chompoopong S, Lertsirithong A, Ariyawatkul T, Sangvichien S.Anatomy of greater palatine foramen and canal and pterygopalatine fossa in Thais: Considerations for maxillary nerve block.Surgical and Radiologic Anatomy 2005;27(6):511-6.

[8]. Kenneth L Reed, Stanley F Malamed, Andrea M Fonner.Anesth Prog 2012;59(3):127-37.
[9]. Saralaya V, Nayak SR. The relative position of the greater palatine foramen in dry Indian skulls. Singapore Med J 2007;48(12):1143-46.

[10]. Ajmani ML. Anatomical variation in position of the greater palatine foramen in the adult human skull. J Anat1994;184:635-37.

[11]. Hassanali J, Mwaniki D. Palatal analysis and osteology of the hard palate of the Kenyan African skulls. Anat Rec 1984;209(2):273-80.

[12]. Westmoreland EE, Blanton PL.An analysis of the variations in position of the greater palatine foramen in the adult human skull.Anat Rec $1982 ; 204(4): 383-8$.

[13]. Cheung LK, Fung SC, Li T, Samman N. Posterior maxillary anatomy: Implications for Le Fort 1 osteotomy. Int J Oral Maxillofac Surg 1998;27:34651.

[14]. Langenegger JJ, Lownie JF, Cleaton-Jones PE. The relationship of the greater palatine foramen to the molar teeth and pterygoid hamulus in human skulls. J Dent 1983;11:249-53.

[15]. Malamed SF, Norman Trieger. Intraoral maxillary nerve block: An anatomical and clinical study. Anesthesia Progress 1983;30(2):44-48.

How to cite this article:

Aravinth Mahesh, Rajesh.S. A study of greater palatine foramen and its importance in the application of maxillary nerve block in South Indian Population. Int J Anat Res 2021;9(1.1):7857-7860. DOI: 10.16965/ijar.2020.244 